\title{
Prevalence of undernutrition and effectiveness of a community- based nutritional support programme to reverse stunting among children under five years of age in an urban slum in Kolkata, India: findings of a one-year longitudinal study
}

\author{
Marcello S Scopazzini', Violette Raoultt', Saumya Kuruttuparambil ${ }^{3}$, Esther Sulkers ${ }^{4}$ \\ ${ }^{1}$ Calcutta Rescue, Kolkata, West Bengal, India; Regional Infectious Diseases Unit, Western General Hospital, NHS Lothian, Edinburgh, UK, 2 Calcutta \\ Rescue, Kolkata, West Bengal, India; Centre Hospitalier Delafontaine, St-Denis, France, ${ }^{3}$ Calcutta Rescue, Kolkata, West Bengal, India; University \\ Children's Hospital Zurich, Switzerland, ${ }^{4}$ Calcutta Rescue, Kolkata, West Bengal, India; Department of Health Sciences, University Medical Centre \\ Groningen, University of Groningen, Groningen, Netherlands \\ Keywords: children, urban slums, india, stunting, undernutrition \\ https://doi.org/10.29392/001c.21942
}

\section{Journal of Global Health Reports}

Vol. 5, 2021

\begin{abstract}
Background
Stunting, defined as z-score height-for-age $(\mathrm{HAZ})<-2$, is an important contributor to the burden of childhood undernutrition among slum-dwelling residents in India's metropolitan areas. Calcutta Rescue (CR) is a non-governmental organisation that provides medical care and nutritional support to slum-dwellers in Kolkata, India. CR undertook a study in Liluah Bhagar, an urban slum, to 1) establish the prevalence of undernutrition among children under five years of age, 2) evaluate the impact of a pilot nutritional support programme on growth patterns of a consecutively selected group of stunted children, and 3) identify socio-economic predictors of stunting.
\end{abstract}

\section{Methods}

For the prevalence assessment (April-June 2018), we conducted anthropometric measurements using standardised World Health Organization (WHO) growth measurements for weight-for-age (WAZ), height-for-age (HAZ), and weight-for-height (WFH). For the longitudinal study, we recruited stunted children and collected anthropomorphic data every three months for one year (December 2018-December 2019).

\section{Results}

The prevalence assessment of 116 children revealed $59 \%$ of stunting, $44 \%$ underweight and $12 \%$ of wasting. Follow-up of 42 stunted children in a pilot nutritional programme improved stunting over time ( $b=0.07,95 \%$ CI 0.05 to $0.039, P<0.001$ ), with a trend towards clinical improvement at one year. Linear mixed model analysis revealed household income was a negative predictor of stunting ( $b=-0.38,95 \%$ CI -0.66 to $-0.09, P=0.010)$.

\section{Conclusions}

This study highlights the burden of undernutrition in marginalised slum-dwelling children in India and the benefits of a pragmatic, education-focused nutritional intervention programme. Further studies are required to determine what predictors other than income are associated with stunting to then determine what interventions are likely to effect long-lasting and sustainable changes to growth in this vulnerable population.

Childhood undernutrition, which includes underweight (low weight-for-age, or WAZ), wasting (low weight-forheight, WFH), stunting (low height-for-age, or HAZ) and micronutrient deficiencies, is a persisting problem in India where the national under-five prevalence of wasting (20.8\%) and stunting (37.9\%) is higher than the developing country average of $8.9 \%$ and $25 \%$, respectively. ${ }^{1}$

Undernutrition in early childhood has far reaching consequences: recent data indicate that malnutrition is the sin- gle biggest contributing risk factor in up to $68.7 \%$ of deaths in children aged 5 years and under. $^{2}$ Other studies have linked undernutrition and stunting in early childhood to impaired cognitive development, increased risk of disease, and suboptimal productivity in later life. ${ }^{2-5}$

Whilst sustained economic growth in the last 20 years has lifted millions out of poverty in India, persisting social inequalities contribute to a high burden of poverty-related illnesses that are particularly marked in urban slums. 5,6 
Poverty is an important driver of undernutrition ${ }^{4}$ : the urban poor have limited access to nutritious foodstuffs and are limited in their knowledge, attitudes, and practices regarding the benefits of healthy nutrition.

Moreover, poor sanitation and unsafe water supplies contribute to high rates of communicable and non-communicable diseases among slum-dwellers, affecting intestinal absorption of micro-nutrients and reducing appetite. This suggests that the prevalence of undernutrition among under-fives living in slum areas in India is higher still than the national average, but data from urban settings are heterogenous $^{5-12}$ or not applicable because they describe findings in other age groups ${ }^{13,14}$ and/or rural settings. ${ }^{15}$

To date, diagnostic and treatment guidelines endorsed by the World Health Organization have focused on reducing mortality associated with acute severe and moderate malnutrition (wasting), but few studies have produced guidance on re-establishing healthy growth in stunted children, and further research in this area is urgently needed. ${ }^{2,16-18}$

Calcutta Rescue is a non-governmental organization (NGO) providing medical care and health education through its Street Medicine Programme to slum-dwellers in Kolkata, India's third largest city. ${ }^{19}$ Approximately $30 \%$ of Kolkata's residents are classed as slum-dwellers. ${ }^{20}$

We present outcome data of a study that aimed to: 1) establish the prevalence of stunting, wasting and underweight in children aged 0-5 years attending the Street Medicine Programme, 2) evaluate the impact of a pilot nutritional intervention programme by longitudinally assessing its effect on growth patterns of a consecutively selected group of stunted children, and 3) identify socio-demographic predictors of height-for-age (stunting) in Liluah Bhagar, a large urban slum in CR's catchment area.

\section{METHODS}

\section{STUDY SITE}

The nutritional programme was launched in Liluah Bhagar (LB), a large slum in North-Western Kolkata, India and monitored children aged $<5$ presenting for care at Calcutta Rescue's street medicine ambulance service between April 2018 and January 2020. LB is a slum with an estimated population of 2,200 persons. LB is a permanent, multi-generational slum with a predominantly Hindu population and generates economic activity from a nearby garbage dump. CR began its mobile health clinic in LB in April 2018. Following a townhall meeting during which residents were invited to suggest clinical services they felt were most needed, CR developed a holistic primary care programme that provided catch-up vaccination, routine medical care, health education and promotion, and a pilot nutritional support programme.

\section{PARTICIPANTS AND PROCEDURE}

The study consisted of two parts: the first was a pointprevalence assessment of undernutrition and the second a longitudinal evaluation of consecutively recruited children aged $<5$ with clinical evidence of malnutrition, stunting and wasting. For this paper, only the data pertaining to children with stunting were used.
Eligible participants for the study were children 0-5 years, living in LB who visited the outreach programme during the study period, whose parents verbally consented to participating. The study was performed in accordance with the ethical standards laid down in the 1964 Declaration of Helsinki and its later amendments. Verbal informed consent was obtained from parents to analyse anonymised growth data of children recruited to the study.

\section{PREVALENCE ASSESSMENT}

For the prevalence assessment, all children aged $<5$ years who visited the outreach programme between April and June 2018 were included. Height, weight, and mid-upper arm circumference (MUAC) were recorded for 116 children, and data were entered on WHO Anthro software for assessing growth and development of children (WHO Anthro for personal computers, version 3.2.2, 2011. Geneva: WHO, 2010). MUAC was recorded for all children aged 6 months -5 years.

\section{EVALUATION OF THE OUTCOMES OF THE NUTRITIONAL SUPPORT PROGRAMME}

The second part of the study focused on stunted children only. Those who were identified as stunted (defined as height-for-age score below $z-2$ ) during the first part of the study and children who were diagnosed with stunting later (between April and December 2018) were eligible for participation.

Parents were informed about the programme by a staff member of CR's street medicine team. After obtaining informed consent from the parent, the child was admitted to a one-year nutritional intervention programme. A total of 53 children were admitted to the programme which consisted of the following components: (i) distribution of prophylactic anthelminthic treatment and micronutrient supplementation in line with Indian and WHO guidelines; (ii) distribution of nutritional benefit bags and supplementary feeding to families with children identified as undernourished; (iii) promotion of exclusive breastfeeding; and (iv) maternal nutritional education. Measurements of weight and height were taken at baseline and follow-up assessments occurred every 3 months for one year.

\section{MEASURES}

\section{NUTRITIONAL STATUS}

The nutritional assessment consisted of weight and height. The measurements were performed by CR street medicine staff who received formal training and supervision throughout the programme from three medical doctors (MS, SK, and VR) with experience in child health volunteering for the organisation. Weight was measured using calibrated digital scales. Height was measured using a calibrated mobile stadiometer (seca ${ }^{\circledR} 213$ portable stadiometer) for children of walking age and a portable infantometer (seca ${ }^{\circledR} 210$ mobile measuring mat) for children aged $<1$ year. The data were entered in the WHO Anthro program to calculate $Z$-scores for height-for-age (HAZ) and weight-for-age (WAZ) using WHO reference values. ${ }^{21}$ 
Table 1. Prevalence of different forms of undernutrition by age and gender $(n=116)$

\begin{tabular}{|c|c|c|c|c|c|c|c|c|c|}
\hline & \multicolumn{2}{|c|}{ Weight for height } & \multicolumn{3}{|c|}{ Height for age } & \multicolumn{4}{|c|}{ Weight for age } \\
\hline & Wasted & Normal & $P$ & Stunted & Normal & $P$ & $\frac{\text { Under- }}{\text { weight }}$ & normal & $P$ \\
\hline $\begin{array}{l}\text { Age } \\
\text { (months) }\end{array}$ & & & 0.415 & & & 0.278 & & & 0.288 \\
\hline $0-23$ & $\begin{array}{c}10.1 \% \\
(7)\end{array}$ & $\begin{array}{c}89.9 \% \\
(62)\end{array}$ & & $\begin{array}{c}55.1 \% \\
(38)\end{array}$ & $\begin{array}{c}44.9 \% \\
(31)\end{array}$ & & $\begin{array}{c}40.0 \% \\
(28)\end{array}$ & $\begin{array}{c}60.0 \% \\
(42)\end{array}$ & \\
\hline $24-59$ & $\begin{array}{l}15.2 \% \\
(7)\end{array}$ & $\begin{array}{c}84.8 \% \\
(39)\end{array}$ & & $\begin{array}{c}65.2 \% \\
(30)\end{array}$ & $\begin{array}{c}34.8 \% \\
(16)\end{array}$ & & $\begin{array}{c}50.0 \% \\
(23)\end{array}$ & $\begin{array}{c}50.0 \% \\
(23)\end{array}$ & \\
\hline Gender & & & 0.650 & & & 0.66 & & & 0.743 \\
\hline Female & $\begin{array}{c}13.7 \% \\
(7)\end{array}$ & $\begin{array}{c}86.3 \% \\
(44)\end{array}$ & & $\begin{array}{c}56.9 \% \\
(29)\end{array}$ & $\begin{array}{c}43.1 \% \\
(22)\end{array}$ & 0.659 & $\begin{array}{c}42.2 \% \\
(22)\end{array}$ & $\begin{array}{c}57.7 \% \\
(30)\end{array}$ & \\
\hline Male & $\begin{array}{c}10.9 \% \\
(7)\end{array}$ & $\begin{array}{c}89.1 \% \\
(57)\end{array}$ & & $\begin{array}{c}60.9 \% \\
(39)\end{array}$ & $\begin{array}{c}39.1 \% \\
(25)\end{array}$ & & $\begin{array}{l}45.3 \% \\
(29)\end{array}$ & $\begin{array}{l}54.7 \% \\
(35)\end{array}$ & \\
\hline TOTAL & $\begin{array}{c}12.2 \% \\
(14)\end{array}$ & $\begin{array}{c}87.8 \% \\
(101)\end{array}$ & & $\begin{array}{c}59.1 \% \\
(68)\end{array}$ & $\begin{array}{c}40.9 \% \\
(47)\end{array}$ & & $\begin{array}{c}44.0 \% \\
(51)\end{array}$ & $\begin{array}{c}56.9 \% \\
(65)\end{array}$ & \\
\hline
\end{tabular}

\section{RELATED FACTORS}

The following factors were included in the analysis: age, gender, household size, number of siblings, household income per capita and maternal education.

\section{STATISTICAL ANALYSIS}

Data were collected using a case record form purposefully designed for the nutritional programme. Paper case record forms were stored under lock and key in CR's street medicine offices. Each child was provided with a numerical identifier that ensured appropriate anonymization of identifiable data. Data were then transferred manually into a Microsoft Excel (2013) spreadsheet which was password protected. All data were subsequently transferred to and analysed in a password protected database in IBM SPSS Statistics for Windows, version 26.0 (IBM SPSS, Inc., Chicago, IL).

The prevalence of stunting, wasting and underweight was determined by computing the percentage of children aged $<5$ years whose z-scores for HAZ, WAZ and WFH fell -2 standard deviations from the median height-for-age/ weight-for-age of the WHO Child Growth Standards divided by the total number of children aged $0-5$ years who were measured and multiplied by 100 . The association of underweight with age and gender was analysed by chi-square test.

Means, standard deviations and percentages were used to describe the characteristics of the children admitted to the longitudinal study. The Mann-Whitney U test was used to compare the group who left the study with those who remained in the study.

The evaluation of a pilot integrated nutritional intervention programme on a consecutively selected group of stunted children and subsequent longitudinal analysis of socio-demographic predictors of stunting were carried out by linear mixed model analysis. An advantage of this approach is that missing data poses no problems. ${ }^{22}$ Analyses began with an examination of the pattern and rate of change in HAZ over time. Next, the predictive effect of the socio-demographic factors on change in HAZ over time was tested using univariate analyses. The small sample size precluded the construction of a multivariate regression model. $P$-values less than 0.05 were considered significant.

\section{RESULTS}

\section{PREVALENCE ASSESSMENT}

\section{SAMPLE CHARACTERISTICS}

The sample of the first part of the study consisted of 116 children (64 boys and 52 girls). Approximately two thirds $(62.1 \%, n=72)$ of the children examined in the study belonged to the age group 0-24 months.

\section{PREVALENCE OF WASTING, STUNTING AND UNDERWEIGHT}

The prevalence assessment revealed that $12.2 \%(n=14)$ of children $<5$ were wasted, $59.1 \%(n=68)$ were stunted and 44.0\% ( $n=51$ ) were underweight. Different forms of undernutrition coexisted in two-thirds of the sample. Table 1 shows the distribution of stunting and wasting across age and gender. The results show there was no significant association between age and wasting $\left(\chi^{2}=0.66, P=0.415\right)$ stunting $\left(\chi^{2}=1.18, P=0.278\right)$ or underweight $\left(\chi^{2}=1.13, P=0.288\right)$. Similar results were found for the relationship between gender and wasting $\left(\chi^{2}=0.21, \quad P=0.650\right)$, stunting $\left(\chi^{2}=0.20, P=0.659\right)$ and underweight $\left(\chi^{2}=0.101, P=0.743\right)$.

\section{LONGITUDINAL STUDY ASSESSING THE IMPACT OF THE NUTRITIONAL INTERVENTION PROGRAMME}

\section{SAMPLE CHARACTERISTICS}

A total of 53 stunted children were included. During the study period, 11 children left the study (drop-out rate $21 \%$ ). Reasons for drop-out were: distance from the street medicine programme; return to rural villages; and disinterest in 


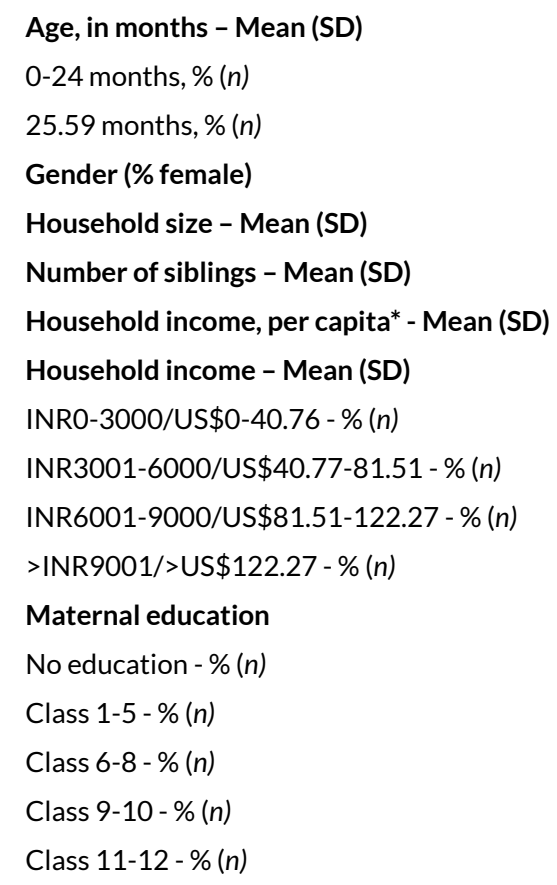

$24.98(11.13)$
$42.9 \%(18)$
$57.1 \%(24)$
$38.1 \%(16)$
$5.64(1.85)$
$1.55(1.00)$
INR $1013 /$ US\$ $\$ 13.76 \S$ (INR477/US\$6.48)
INR5172/US\$70.26§ (INR1949/US $\$ 26.48)$
$12.1 \%(4)$
$69.7 \%(23)$
$15.2 \%(15)$
$4 \%(1)$
$42.4 \%(14)$
$24.2 \%(8)$
$24.2 \%(8)$
$6.1 \%(2)$
$3 \%(1)$

Note: *based on $n=33$ (due to missing data); $†$ INR=Indian Rupee; $\ddagger$ US $\$=U S ;$ §median = INR900; §median = INR4500.

the programme. The HAZ at baseline of the 11 children who left the study ( $M d n=-2.92)$ did not differ significantly from those who remained in the study $(M d n=-2.84), U=272.50, P$ $=0.676$ ). The final sample consisted of 42 children (Table 2).

\section{NUTRITIONAL STATUS ACROSS THE STUDY PERIOD}

HAZ of enrolled children was reassessed at three-monthly intervals. The percentage of stunted children decreased over time but remained above $80 \%$ across the study period.

There was a statistically significant improvement in HAZ over time ( $b=0.07,95 \%$ CI 0.05 to $0.039, P<0.001$ ), and a trend towards clinical resolution of stunting. HAZ at all timepoints remained below the critical cut-off for stunting (below $z-2$ ).

\section{FACTORS RELATED TO CHANGE IN HAZ OVER TIME}

The results of the multilevel analyses showed that of all predictors (age, gender, household size, number of siblings, maternal education) only income was significantly associated with HAZ (see table 3). The HAZ of children from households with lower incomes per capita was lower $(b$ $=-0.38,95 \%$ CI -0.66 to $-0.09, P=0.01$ ) than those of children coming from more affluent households (income per capita above the median).

\section{DISCUSSION}

In this study, we present data on the prevalence of undernutrition and the impact of a nutritional intervention programme targeting stunted children living in a slum in Kolkata, India. We found prevalence rates of $12.2 \%$ for wasting, $59.1 \%$ for stunting, and $44.0 \%$ for underweight. The results of the subsequent multi-component nutritional intervention programme targeting a sample of stunted children recruited to a one-year longitudinal study showed a significant improvement in height-for-age z-scores (HAZ) at one year.

The results of our point-prevalence assessment of nutritional status supported anecdotal evidence of poor nutritional outcomes in our study population, and was in line with prevalence estimates from other studies in urban slums in India ${ }^{6,12}$ describing serious and continuing risk of undernutrition in children aged under five who live in urban slums. As predicted, these estimates are much higher than the national prevalence of undernutrition, ${ }^{1}$ which is already worse than those of other comparable low- and middle-income countries (LMICs). We recognise that our small sample size precludes us from drawing definitive conclusions, and this is a major limitation of our prevalence assessment.

Whereas morbidity and mortality outcomes related to severe or moderate acute malnutrition (wasting) are well described, and effective, WHO-endorsed standardised interventions exist, the burden of stunting - as defined by low height-for-age (HAZ) - is less well characterised.

The results of our multi-component nutritional intervention programme showed a significant improvement in HAZ over time, but most children did not recover from stunting during the one-year intervention period. Previous studies have shown similar findings: a study reporting the effectiveness of a stunting recovery programme in Brazil, which provided intensive treatment in a specialised centre for at least 24 months, showed that only $24 \%$ of children 
Table 3. Parameter estimates for multilevel models of HAZ predicted by time* and socio-demographic factors

\begin{tabular}{|c|c|c|c|}
\hline & $\beta$ & $95 \% \mathrm{Cl}$ & Pvalue \\
\hline \multicolumn{4}{|l|}{ Age } \\
\hline Intercept & -2.96 & & \\
\hline Time since baseline & 0.07 & $0.05-0.10$ & $<0.001$ \\
\hline Age $0-24$ months & 0.15 & $-0.18-0.48$ & 0.375 \\
\hline Age $25-59$ months & 0 & - & - \\
\hline \multicolumn{4}{|l|}{ Gender } \\
\hline Intercept & -2.88 & & \\
\hline Time since baseline & 0.07 & $0.05-0.10$ & $<0.001$ \\
\hline Female & -0.04 & $-0.39-0.30$ & 0.798 \\
\hline Male & 0 & - & - \\
\hline \multicolumn{4}{|l|}{ Household size } \\
\hline Intercept & -2.53 & & \\
\hline Time since baseline & 0.09 & $0.07-0.12$ & $<0.001$ \\
\hline Household size & -0.06 & $-0.14-0.02$ & 0.154 \\
\hline \multicolumn{4}{|l|}{ Number of siblings } \\
\hline Intercept & -2.68 & - & - \\
\hline Time since baseline & 0.09 & $0.07-0.12$ & $<0.001$ \\
\hline Number of siblings & -0.12 & $-0.27-0.03$ & 0.120 \\
\hline \multicolumn{4}{|l|}{ Maternal education } \\
\hline Intercept & -2.81 & - & - \\
\hline Time since baseline & 0.09 & $0.07-0.12$ & $<0.001$ \\
\hline Illiterate & -0.12 & $-0.43-0.20$ & 0.452 \\
\hline Literate & 0 & - & - \\
\hline \multicolumn{4}{|l|}{ Income per capita } \\
\hline Intercept & -2.67 & - & - \\
\hline Time since baseline & 0.09 & $0.07-0.12$ & $<0.001$ \\
\hline$\leq$ Median income $\mathrm{PC}$ & -0.38 & $-0.66-0.09$ & 0.011 \\
\hline > Median income PC & 0 & - & - \\
\hline
\end{tabular}

Notes: *Average change in HAZ per 3 months

admitted to that programme recovered from stunting. This is in part explained by the difficulty in achieving catch-up growth in children beyond their $1000^{\text {th }}$ day of life inclusive of gestation (approximately 2 years of age). ${ }^{18}$ Approximately $60 \%$ of our sample was beyond 24 months of age, and this fact, combined with the extreme poverty of our study setting, helps in part explain our inability to reverse stunting within the year's timeframe.

Despite our expectations, change in HAZ over time was only related to income and not to any other of socio-demographic factors we inserted in our regression model. Our findings can be explained by the restricted range - where we only considered stunted children - causing low or insignificant associations between predictors and the outcome. Evidence from previous research indeed indicates that children from poorer households are at increased risk of stunting and unconditional cash transfers have been recently evaluated as a means of improving nutrition through poverty alleviation, but results are mixed 23,24 : in a recent study evaluating the impact on growth of a four-year unconditional cash transfer programme in a deeply impoverished area of Zambia, Chakrabarti et al reported no change in HAZ over time because other factors, such as access to healthcare, maternal education, and the disease environment, among others, did not appreciably improve over time. ${ }^{25}$ This further underscores that stunting is a multi-faceted condition, which, when established, is difficult to treat.

Our study did not address prevention of stunting, but we recognise this as an urgent priority as outlined in the 2030 agenda for sustainable development. Evidence suggests the "first 1000 days" are a crucial window in a child's life during which stunting can be most effectively prevented. Further, the nutritional status of expectant mothers impacts foetal growth, birthweight, and linear growth in the first two years of life. Studies have shown that women with low pre-pregnancy height, weight and BMI are at increased risk of having a stunted child at 2 years of age. ${ }^{26}$ The " 1000 day plus" concept unified targeted responses to nutrition in the pre-conception phase and the first 1000 days of life to address the dependent relationship between maternal, foetal and child 
nutritional status. Investment in this period has the potential to yield benefits not only for the child's lifetime, but across multiple generations. ${ }^{18}$

Our study has several strengths. We successfully identified and quantified undernutrition in challenging circumstances and evaluated the impact of a nutritional programme that was acceptable to the local community. To date, evidence in support of nutritional programmes aiming to reverse or prevent stunting have largely focused on rural areas in low- and middle-income countries and there is a lack of evidence concerning urban slum dwelling populations. Our study is therefore among the first whose aim was to evaluate the impact of a longitudinal nutritional support programme targeting stunting in a group of urban slumdwelling children.

We also identified several limitations: our sample size was small, and further hampered by loss to follow-up. We recognise that this may have contributed to an increased selection bias, which in turn may have disproportionately influenced our final effect size and direction. Our study included children up to five years, but we know from evidence that stunting is irreversibly established beyond the first 1000 days of life inclusive of gestation. The impetus of our nutritional support programme was such that we could not ethically justify withholding nutritional support from children who were older than this cut-off.

Our study underscores that undernutrition is highly prevalent in urban slums and is a persisting problem despite recent vaunted economic gains in India, many of which have not positively impacted the very poor. We demonstrate encouraging results of a pragmatic, education-focused, nutritional support programme that aimed to tackle stunting in a large slum in Kolkata. The urgency of our study was fuelled by our knowledge that undernutrition has lifelong and intergenerational consequences as identified by the recent Lancet series on the burden of malnutrition, ${ }^{18}$ and increasing international focus on the need to break this cycle.

We hope to achieve our aim of reversing stunting by replicating our pilot model in other slum areas in which Calcutta Rescue operates to increase the size of our sample, adjusting for baseline differences in slum areas.

Subsequent studies may consider including a broader range of predictors at the individual, household, and community levels, for example, medical factors such as prevalent infectious diseases and vaccination status, household characteristics, such water and sanitation infrastructure, and food security within the community.

\section{CONCLUSIONS}

In conclusion, we present results of a point prevalence study of 116 children living in a large slum in Kolkata, India which demonstrates high rates of undernutrition. We further present results of a one-year longitudinal study aiming to quantify the impact of a nutritional support programme over time. Our exploratory findings underline the urgent need for larger-scale studies in urban slums to determine what predictors are associated with stunting at baseline and over time, and what interventions are most likely to effect sustainable changes to growth.

\section{ACKNOWLEDGMENTS}

The authors thank Mr Jaydeep Chakraborty, Chief Executive Officer at CR, Dr Alakananda Ghosh, chief medical officer at $\mathrm{CR}$, the street medicine team of CR who perform extraordinary work with their beneficiaries every day, and Dr Kim Tran Dinh (UK) for their contribution to this work.

\section{FUNDING}

Calcutta Rescue receives funding from private donations. We are grateful to the Avina Foundation, who generously funded the nutritional programme described in this study.

\section{AUTHORSHIP CONTRIBUTIONS}

MS, ES and SK conceived the initial design and completed the prevalence assessment. VR subsequently refined the project and collected data for the longitudinal study, which was analysed by ES. The interpretation was agreed by all authors. MS, ES and VR drafted the manuscript which was critically revised by all authors who agree now to be accountable for all aspects of the work in ensuring that questions related to the accuracy or integrity of any part of the work are appropriately investigated and resolved.

\section{COMPETING INTERESTS}

All authors are volunteers for the organisation Calcutta Rescue and participated in field missions in Kolkata. The authors completed the Unified Competing Interest form at www.icmje.org/coi disclosure.pdf (available upon request from the corresponding author) and declare no conflicts of interest.

\section{CORRESPONDENCE TO:}

Dr Marcello S Scopazzini, MbChB, MSc, MRCP(UK), DTM\&H

Specialist Registrar in Infectious Diseases and General Internal Medicine

8/8 Dicksonfield

Edinburgh

EH7 5ND

Marcello.scopazzini@nhs.scot

Submitted: December 21, 2020 GMT, Accepted: March 09, 2021 GMT 


\section{REFERENCES}

1. India Nutrition Profile - Global Nutrition Report. Accessed October 21, 2020. https://globalnutritionrep ort.org/resources/nutrition-profiles/asia/southern-asi a/india/

2. Swaminathan S, Hemalatha R, Pandey A, et al. The burden of child and maternal malnutrition and trends in its indicators in the states of India: the Global Burden of Disease Study 1990-2017. Lancet Child Adolesc Heal. 2019;3(12):855-870. doi:10.1016/S235 2-4642(19)30273-1

3. Leroy JL, Frongillo EA, Dewan P, Black MM, Waterland RA. Can Children Catch up from the Consequences of Undernourishment? Evidence from Child Linear Growth, Developmental Epigenetics, and Brain and Neurocognitive Development. Adv Nutr. 2020;11(4):1032-1041. doi:10.1093/advances/nmaa02 $\underline{0}$

4. Pena M, Bacallao J. Malnutrition and poverty. Annu Rev of Nutr. 2002;22:241-253. doi:10.1146/annurev.nu tr.22.120701.141104

5. Bhavsar S, Hemant M, Kulkarni R. Maternal and Environmental Factors Affecting the Nutritional Status of Children in Mumbai Urban Slum. Int J Sci Res Publ. 2012;2(11):81-89.

6. Murarkar S, Gothankar J, Doke P, et al. Prevalence and determinants of undernutrition among underfive children residing in urban slums and rural area, Maharashtra, India: a community-based crosssectional study. BMC Public Health. 2020;20(1):1559. doi:10.1186/s12889-020-09642-0

7. Bandyopadhyay S, Das S, Mondal S. Assessment of Undernutrition Among the Under-5 Children in a Slum of Kolkata. ICAN Infant, Child, Adolesc Nutr. 2014;6(1):52-57. doi:10.1177/1941406413513154

8. Nale T, Chavan MK, Mahajan H, Velhal GH. Disentangling the influence of maternal factors on nutritional status of children: community based study in an urban slum of India. Int J Gen Med Pharm. 2013;2(1):45-54.

9. Akhade KS. Measuring malnutrition: needs a comprehensive indicator. Int J Community Med Public Heal. 2017;5(1):258-261. doi:10.18203/2394-6040.ijc mph20175793

10. Dhok R, Thakre S. Chronic undernutrition amongst under-five in an urban slum of Central India. Int J Community Med Public Heal. 2016;3(3):700-704. d oi:10.18203/2394-6040.ijcmph20160636
11. Sengupta P, Benjamin AI. Epidemiological correlates of under-nutrition in under-5 years children in an urban slum of Ludhiana. Heal Popul Perspect issues. 2010;33(1):1-9.

12. Mamulwar MS, Rathod HK, Jethani S, et al. Nutritional status of under-five children in urban slums of Pune. Int J Med Public Heal. 2014;4(3):247-252. doi:10.4103/2230-8598.137710

13. Panigrahi A, Das SC. Undernutrition and Its Correlates among Children of 3-9 Years of Age Residing in Slum Areas of Bhubaneswar, India. Published online 2014. doi:10.1155/2014/719673

14. Huey SL, Finkelstein JL, Venkatramanan S, et al. Prevalence and Correlates of Undernutrition in Young Children Living in Urban Slums of Mumbai, India: A Cross Sectional Study. Front Public Heal. 2019;7. doi:1 $\underline{0.3389 / \text { fpubh.2019.00191 }}$

15. Kumar L. D, Mangal N, Varghese KA, Salvi TC, Salvi PP, Udawat VS. Nutritional assessment of under five children in a rural belt of southern Rajasthan,India. Public Heal Rev Int J Public Heal Res. 2019;6(6):224-233. doi:10.17511/ijphr.2019.i6.03

16. Goudet SM, Bogin BA, Madise NJ, Griffiths PL. Nutritional interventions for preventing stunting in children (Birth to 59 months) living in urban slums in low-and middle-income countries (LMIC). Cochrane Database Syst Rev. 2019;2019(6). doi:10.1002/1465185 8.CD011695.pub2

17. Black RE, Morris SS, Bryce J. Where and why are 10 million children dying every year? Lancet. 2003;361(9376):2226-2234. doi:10.1016/S0140-673 6(03)13779-8

18. Black RE, Victora CG, Walker SP, et al. Maternal and child undernutrition and overweight in lowincome and middle-income countries. Lancet. 2013;382(9890):427-451. doi:10.1016/S0140-6736(1 3)60937-X

19. Lange M. Multidimensional poverty in Kolkata's slums: towards data driven decision making in a medium-sized NGO. J Poverty Soc Justice. Published online 2020. doi:10.1332/175982720X1603477058166 $\underline{5}$

20. Peck D. An Overview of the Economics of Kolkata's Slums. 2018;(January). doi:10.13140/R G.2.2.29748.96641 
21. Onis M. WHO Child Growth Standards based on length/height, weight and age. Acta Paediatr. 2007;95. doi:10.1111/j.1651-2227.2006.tb02378.x

22. Hox JJ. Multilevel analyses of grouped and longitudinal data. In: Little TD, Schnabel KU, Baumert J, Little (Ed) TD, Schnabel (Ed) KU, Baumert (Ed) J, eds. Modeling Longitudinal and Multilevel Data: Practical Issues, Applied Approaches, and Specific Examples. Lawrence Erlbaum Associates Publishers; 2000:15-32.

23. Bommer C, Vollmer S, Subramanian S. How socioeconomic status moderates the stunting-age relationship in low-income and middle-income countries. BMJ Glob Heal. 2019;4(1). doi:10.1136/bmig $\underline{\mathrm{h}-2018-001175}$
24. Pega F, Liu SY, Walter S, Pabayo R, Saith R, Lhachimi SK. Unconditional cash transfers for reducing poverty and vulnerabilities: effect on use of health services and health outcomes in low- and middle-income countries. Cochrane Database Syst Rev. Published online November 15, 2017. doi:10.100 2/14651858.CD011135.pub2

25. Chakrabarti A, Handa S, Natali L, Seidenfeld D, Tembo G. More evidence on the relationship between cash transfers and child height. J Dev Eff. 2020;12(1):14-37. doi:10.1080/19439342.2020.173156 8

26. Young MF, Nguyen PH, Gonzalez Casanova I, et al. Role of maternal preconception nutrition on offspring growth and risk of stunting across the first 1000 days in Vietnam: A prospective cohort study. PLoS One. 2018;13(8). doi:10.1371/journal.pone.0203201 